\begin{tabular}{|c|c|}
\hline 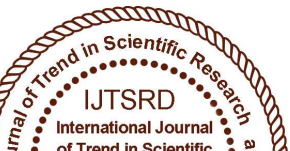 & $\begin{array}{l}\text { International Journal of Trend in Scientific } \\
\text { Research and Development (IJTSRD) }\end{array}$ \\
\hline 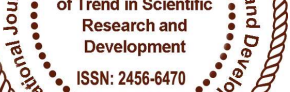 & International Open Access Journal \\
\hline 000 & ISSN No: 2456 - 6470 | www.ijtsrd.com | Volume - 2 | Issue - 3 \\
\hline
\end{tabular}

\title{
Coordination of STATCOM and PSS to Enhance the Power System Stability with Eigen Value Analysis
}

\begin{abstract}
Ankur Patel
Department of Electrical Engineering, C. S. Patel

Institute of Technology, Changa, Gujarat, India
\end{abstract}

\author{
Pratik Mochi \\ Department of Electrical Engineering, C. S. Patel \\ Institute of Technology, Changa, Gujarat, India
}

\section{ABSTRACT}

Transmission networks of modern power systems are becoming increasingly stressed because of growing demand and restrictions on building new lines. One of the consequences of such a stressed system is the threat of losing stability following a disturbance. So for the improvement of power transfer capability with in the safe stability limit it is necessary to enhancing the small signal stability of the power system. The objective of this thesis is to investigate the POWER SYSTEM STABILITY ENHANCEMENT via Automatic Voltage Controller (AVR), Power System Stabilizer (PSS) and Flexible AC Transmission (FACTS) based controller such as Static Synchronous Compensator (STATCOM). This study includes the specific coordination between PSS and STATCOM controller. With use of linearized model of each element the specific parameter will be decided. By the proper coordination of AVR, PSS and STATCOM with specific parameter the stability of the power system will enhance. Above mention coordination maintained the rotor angle and speed in synchronism. Single Machine Infinite Bus system (SMIB) is proposed for the study. Implementation is carried out on the MATLAB / Simulink

Keywords: Power System Stability, STATCOM, PSS

\section{INTRODUCTION}

Power system stability is the ability of the system to remain in operating equilibrium condition and it is shown equilibrium between opposite forces. A classification of power system stability is presented in Fig. 1. As a practical necessity, the classification has been based on a number of diverse considerations, making it difficult to select clearly distinct categories and provide definitions that are rigorous and yet convenient for practical use. For example, there is some overlap between short-term/long-term stability and voltage stability. With appropriate models for loads, on- load tap changers and generator reactive power limits, short-term/long-term stability simulations are ideally suited for dynamic analysis of voltage stability. Similarly, there is overlap between transient, short-term and long-term stability: all three use similar analytical techniques for nonlinear time domain response of the system to large disturbances. Power system stability is classified as rotor angle and voltage stability. Rotor angle is an ability to maintain synchronism in the system and torque balance of synchronous machines [1]. 


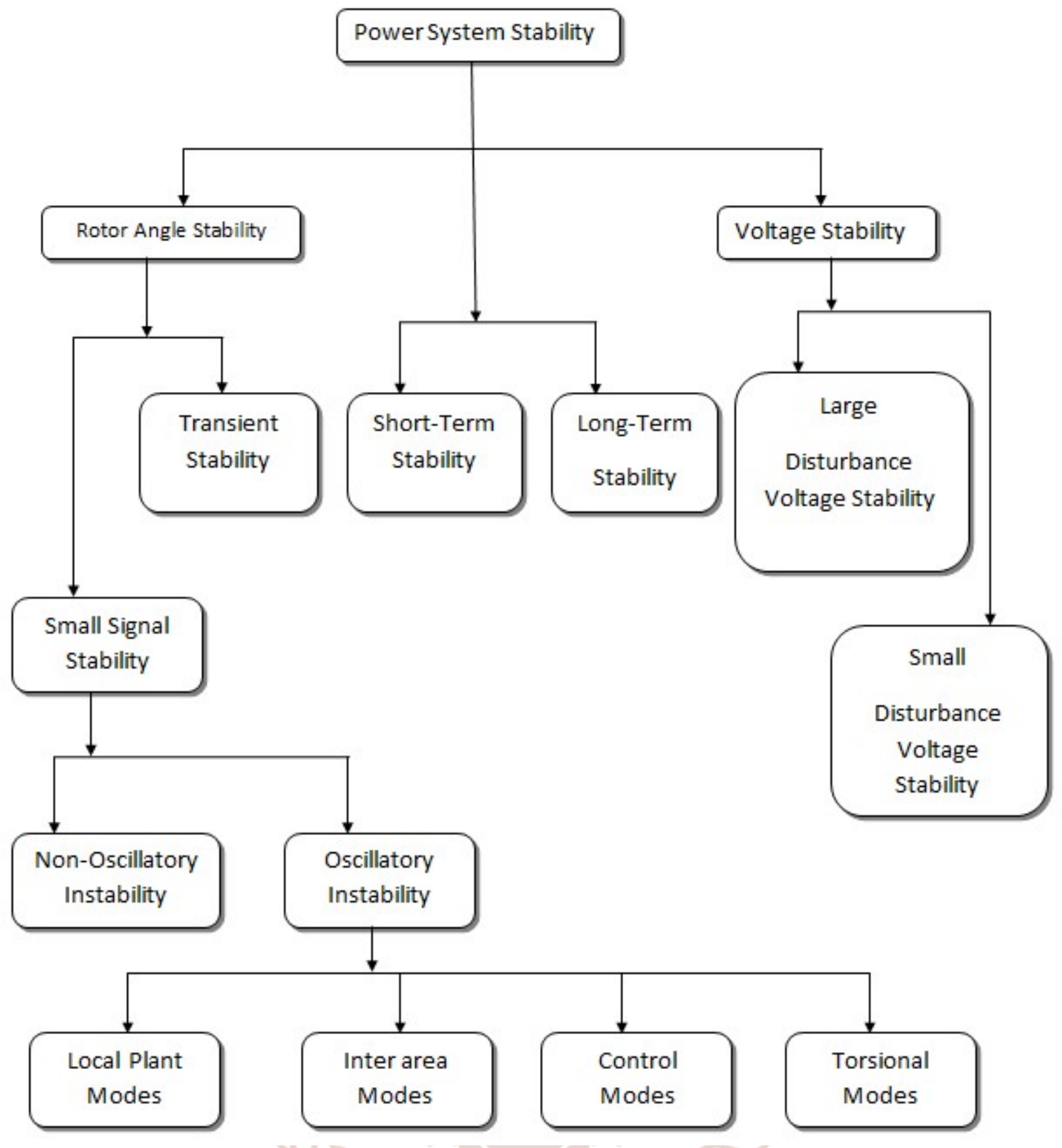

Fig 1 Classification of power system stability

\section{Single Machine Infinite Bus (SMIB) system}

For the transient stability analysis we used the single machine connected to a large system through a transmission Line. Fig. 2 shows the Basic configuration of SMIB system [3]. For the analysis purpose the system reduced to the form fig. 3 by using Thevenin's equivalent of the transmission network external to the machine and the adjacent transmission. Because of the relative size of the system to which the machine is supplying power, dynamics associated with the machine will cause virtually no change in the voltage and frequency of Thevenin's voltage EB. Such a voltage and constant frequency is referred to as an infinite bus [5]. In our study we will begin with the classical model and gradually increase the model detailed by accounting for the effects of the dynamics of the field circuit, excitation system and amortisseurs [4]. In each case, we will develop the expressions for the elements of the state matrix as explicit functions of system parameters. 
International Journal of Trend in Scientific Research and Development (IJTSRD) ISSN: 2456-6470

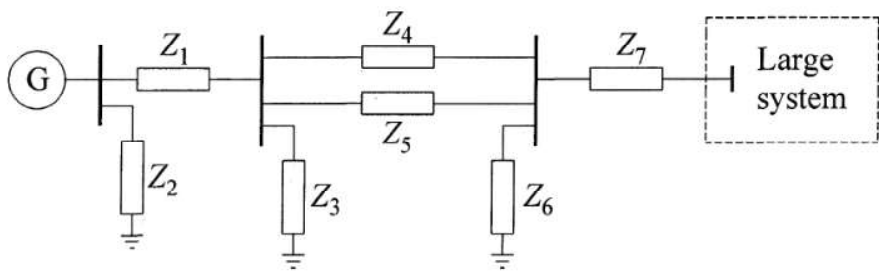

Fig. 2 General configuration of SMIB

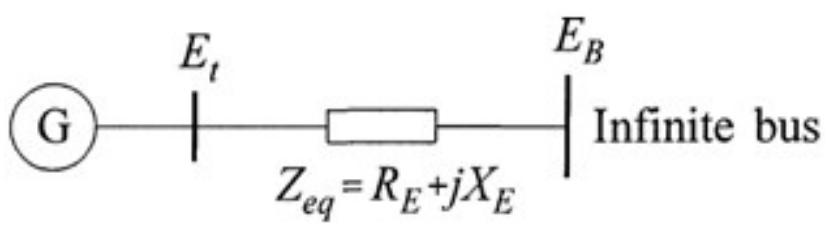

Fig. 3 Equivalent circuit of SMIB system

Linearizing equation of the expression for

$\Delta i_{f d}$ and $\Delta T_{e}$ given by in following matrix form;

$$
\begin{array}{r}
{\left[\begin{array}{c}
\Delta \omega_{r} \\
\dot{\Delta \delta} \\
\dot{\Delta} \psi_{f d}
\end{array}\right]=\left[\begin{array}{ccc}
a_{11} & a_{12} & a_{13} \\
a_{21} & 0 & 0 \\
0 & a_{32} & a_{33}
\end{array}\right]\left[\begin{array}{c}
\Delta \omega_{r} \\
\Delta \delta \\
\Delta \psi_{f d}
\end{array}\right]} \\
+\left[\begin{array}{cc}
b_{11} & 0 \\
0 & 0 \\
0 & b_{32}
\end{array}\right]\left[\begin{array}{c}
\Delta T_{m} \\
\Delta E_{f d}
\end{array}\right]
\end{array}
$$

The complete state -space model for the power system, including the excitation system

$$
\begin{gathered}
{\left[\begin{array}{c}
\Delta \omega_{r} \\
\dot{\Delta \delta} \\
\dot{\Delta} \dot{\psi}_{f d} \\
\dot{\Delta v_{1}}
\end{array}\right]=\left[\begin{array}{cccc}
a_{11} & a_{12} & a_{13} & 0 \\
a_{21} & 0 & 0 & 0 \\
0 & a_{32} & a_{33} & a_{34} \\
0 & a_{42} & a_{43} & a_{44}
\end{array}\right]\left[\begin{array}{c}
\Delta \omega_{r} \\
\Delta \delta \\
\Delta \psi_{f d} \\
\Delta v_{1}
\end{array}\right]} \\
+\left[\begin{array}{c}
b_{1} \\
0 \\
0 \\
0
\end{array}\right] \Delta T_{m}
\end{gathered}
$$

The complete state-space model, including the PSS, has the following form (with $\Delta T_{m}=0$ ) [2]
$\left[\begin{array}{c}\Delta \dot{\omega}_{r} \\ \dot{\delta} \\ \Delta \dot{\psi}_{f d} \\ \Delta \dot{v}_{1} \\ \Delta \dot{v}_{2} \\ \Delta \dot{v}_{s}\end{array}\right]=\left[\begin{array}{cccccc}a_{11} & a_{12} & a_{13} & 0 & 0 & 0 \\ a_{21} & 0 & 0 & 0 & 0 & 0 \\ 0 & a_{32} & a_{33} & a_{34} & 0 & a_{36} \\ 0 & a_{42} & a_{43} & a_{44} & 0 & 0 \\ a_{51} & a_{52} & a_{53} & 0 & a_{55} & 0 \\ a_{61} & a_{62} & a_{63} & 0 & a_{65} & a_{66}\end{array}\right]$

III. i System matrix including STATCOM

So, with the STATCOM our system will modify as below. Finally our system will modified as shown in simulation diagram. By implementing the STATCOM in the system the State Matrix will modified as shown below. The state matrix will modified by the following parameters, $[7,8]$

\section{$\Delta \dot{v}_{d c}=\mathbf{K} 7 \Delta \delta+\mathbf{K} 8 \varphi f d+k 9 \Delta v d c$}

$$
\left[\begin{array}{c}
\Delta \dot{\omega}_{r} \\
\Delta \dot{\delta} \\
\Delta \dot{\varphi}_{f d} \\
\Delta \dot{v}_{1} \\
\Delta \dot{v}_{2} \\
\Delta \dot{v}_{s} \\
\Delta \dot{v}_{d c}
\end{array}\right]=\left[\begin{array}{ccccccc}
a_{11} & a_{12} & a_{13} & 0 & 0 & 0 & a_{17} \\
a_{21} & 0 & 0 & 0 & 0 & 0 & 0 \\
0 & a_{32} & a_{33} & a_{34} & 0 & a_{36} & a_{37} \\
0 & a_{42} & a_{43} & a_{44} & 0 & 0 & 0 \\
a_{51} & a_{52} & a_{53} & 0 & a_{55} & 0 & 0 \\
a_{61} & a_{62} & a_{63} & 0 & a_{65} & a_{66} & 0 \\
0 & a_{72} & a_{73} & 0 & 0 & 0 & a_{77}
\end{array}\right]\left[\begin{array}{c}
\Delta \omega_{r} \\
\Delta \delta \\
\Delta \varphi_{f d} \\
\Delta v_{1} \\
\Delta v_{2} \\
\Delta v_{s} \\
\Delta v_{d c}
\end{array}\right]
$$


International Journal of Trend in Scientific Research and Development (IJTSRD) ISSN: 2456-6470

IV. SIMULATION DIAGRAM

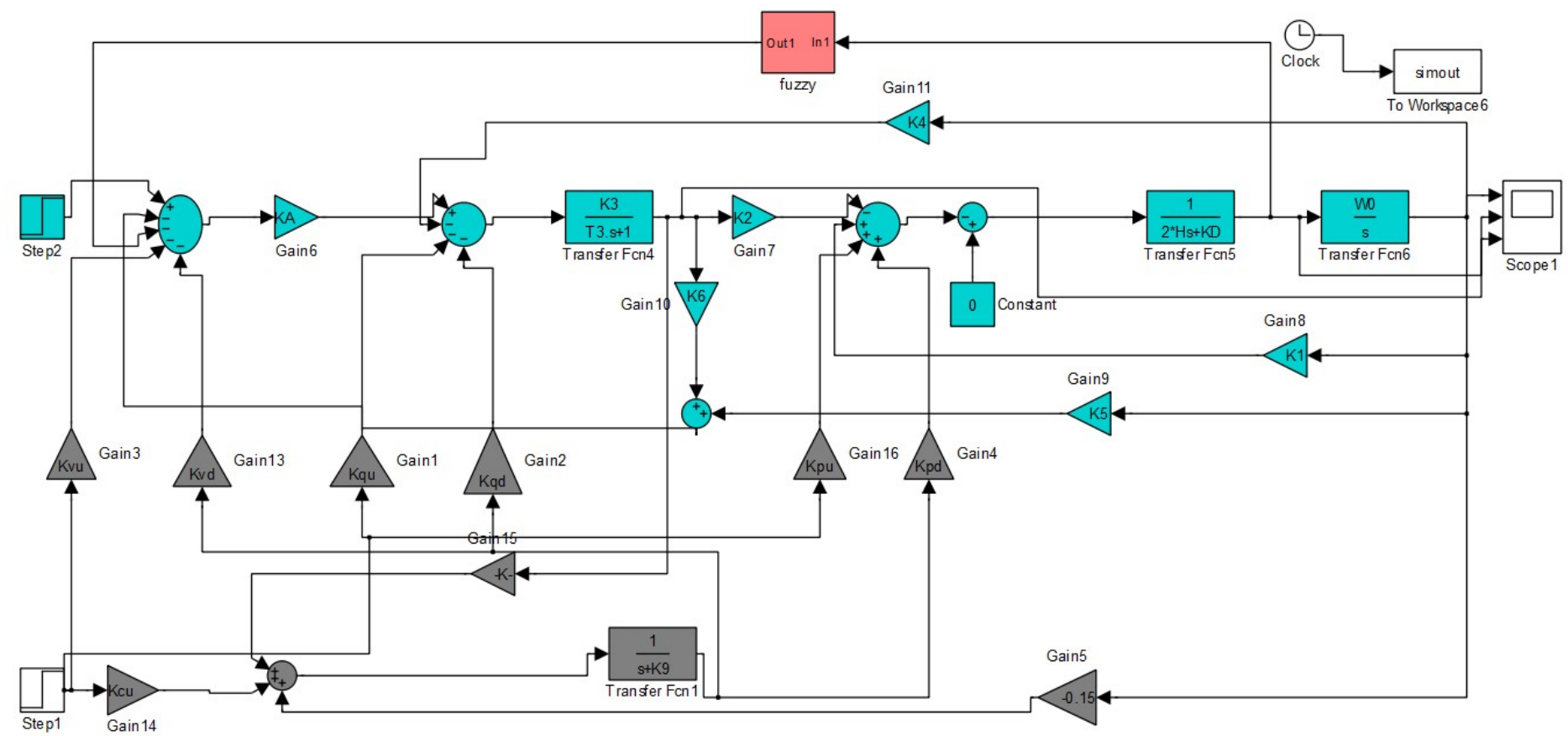

Fig. 4 Simulink Model

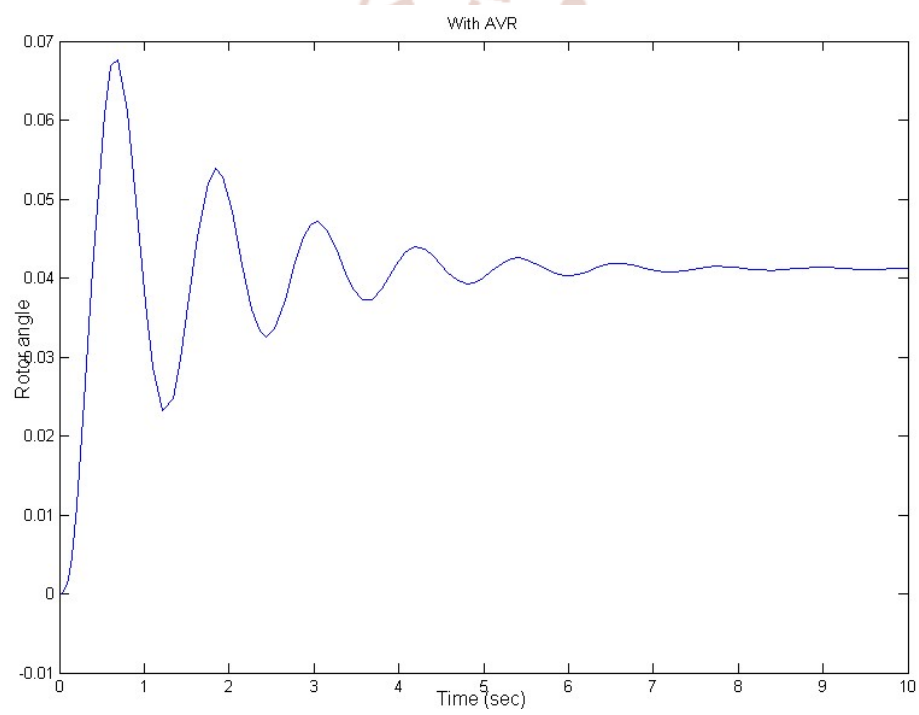

Fig. 5 Rotor angle (With AVR)

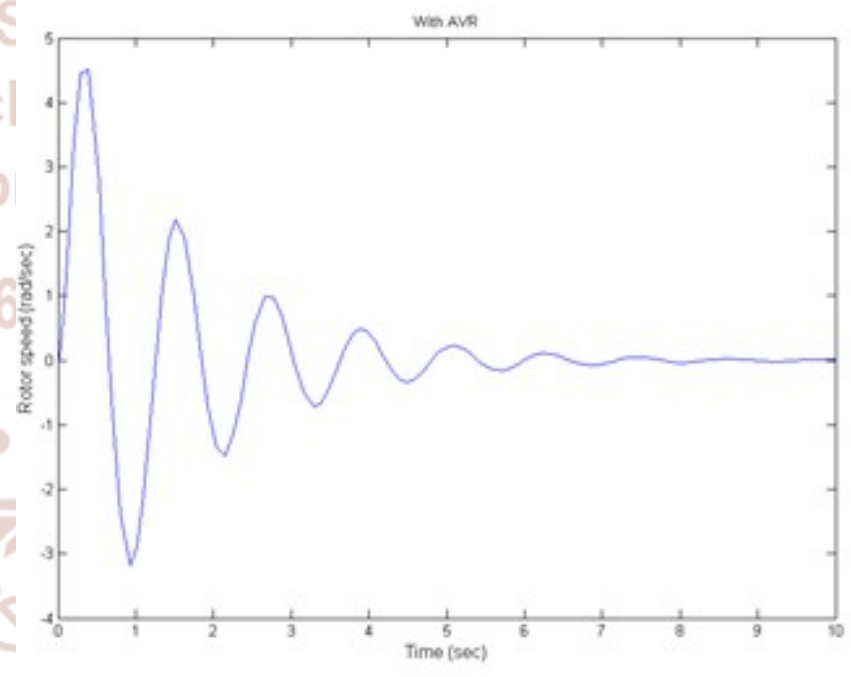

Fig. 6 Rotor speed (With AVR) 
International Journal of Trend in Scientific Research and Development (IJTSRD) ISSN: 2456-6470

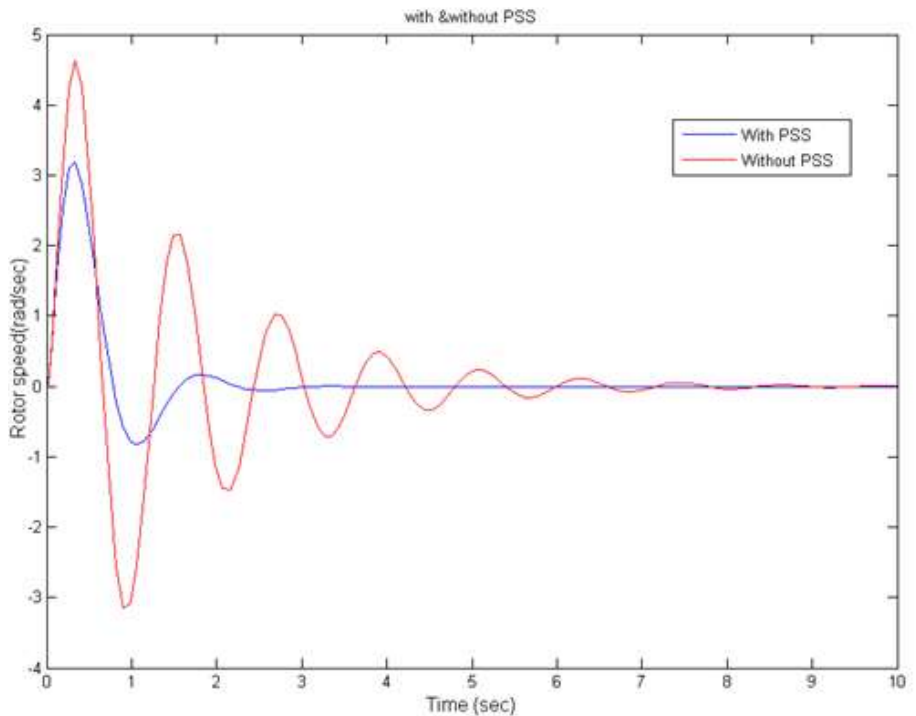

Fig. 7 Rotor speed (With \& without PSS)

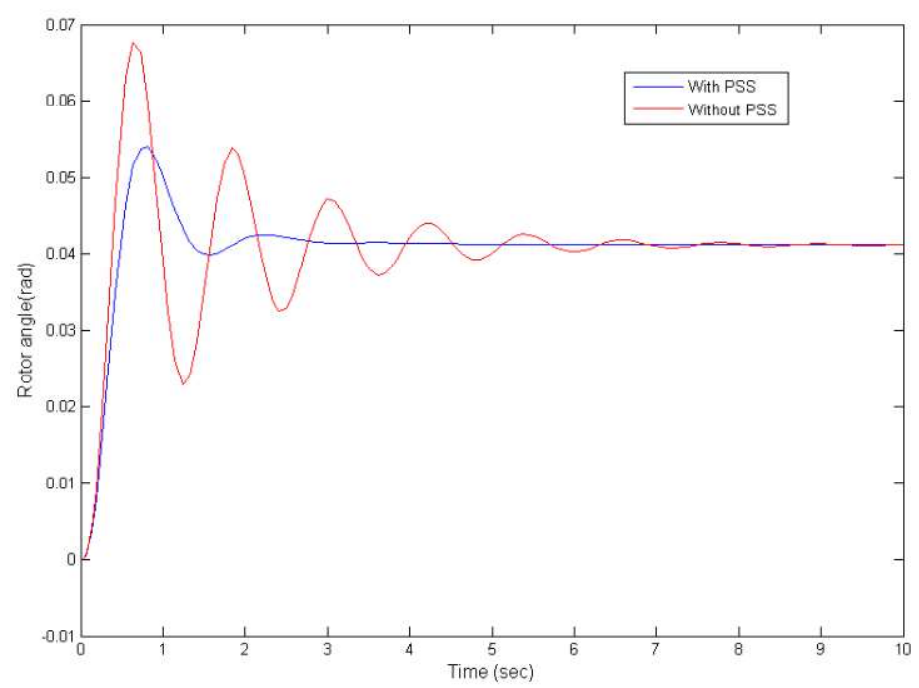

Fig. 8 Rotor angle (With \& without PSS)

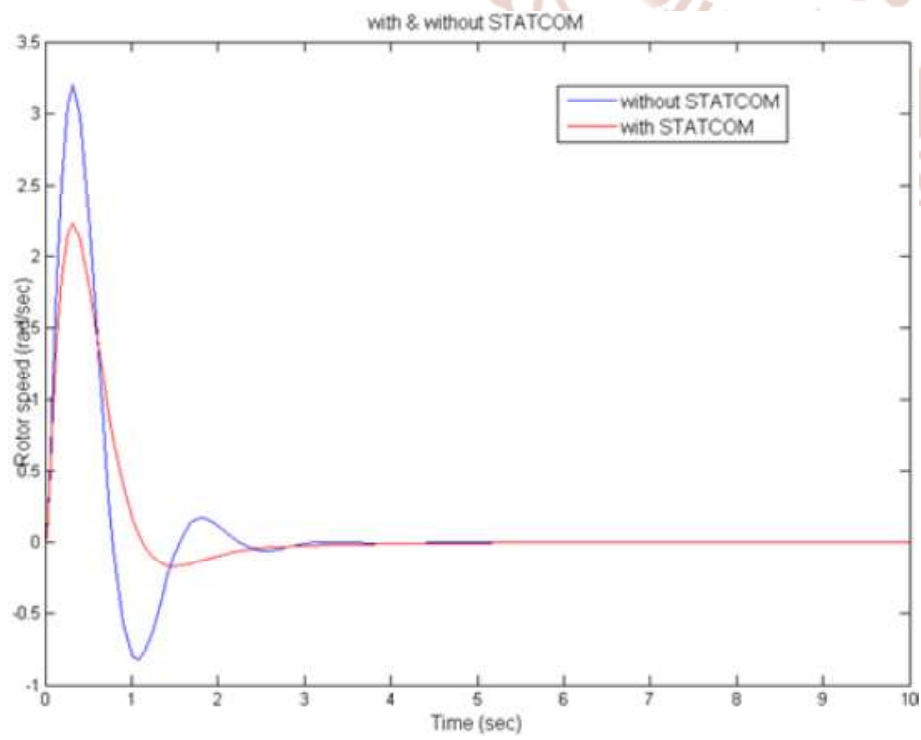

Fig. 9 Rotor speed (With \& without STATCOM)

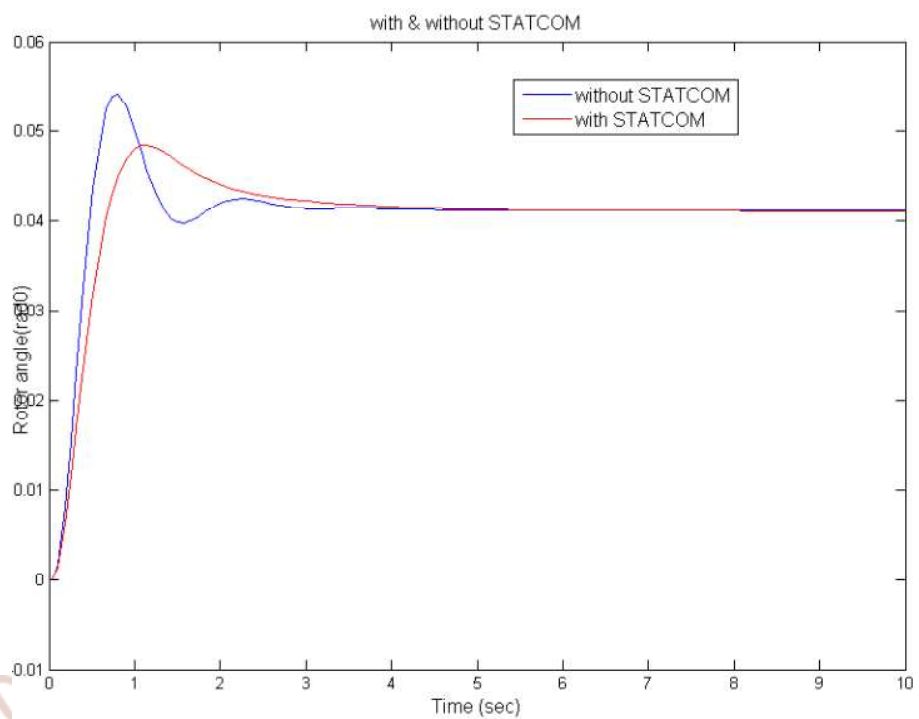

Fig. 10 Rotor angle (With \& without STATCOM)

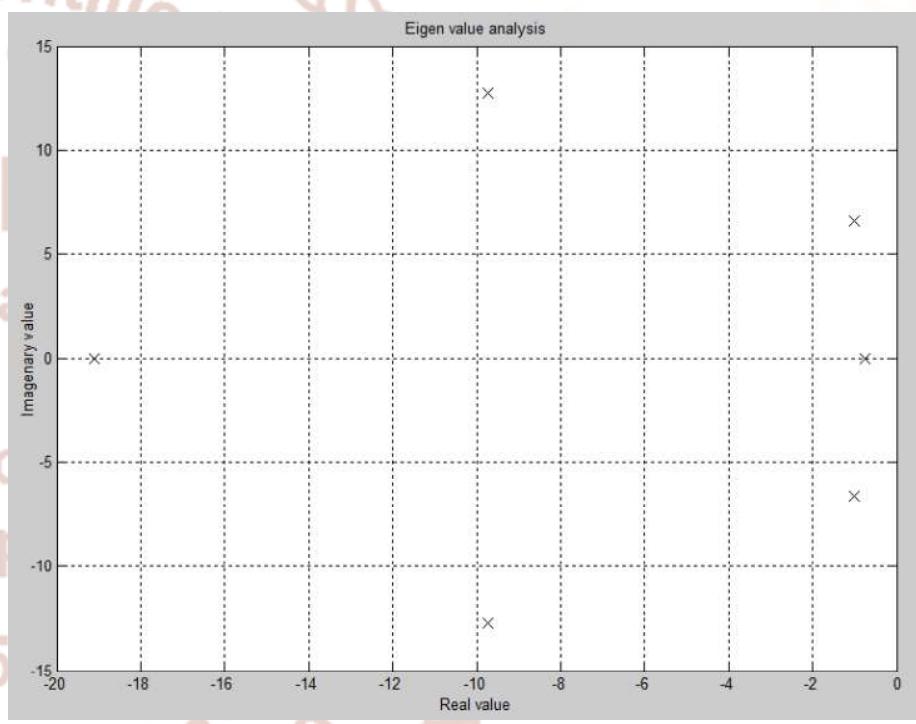

Fig. 11 Eigen values plot with PSS

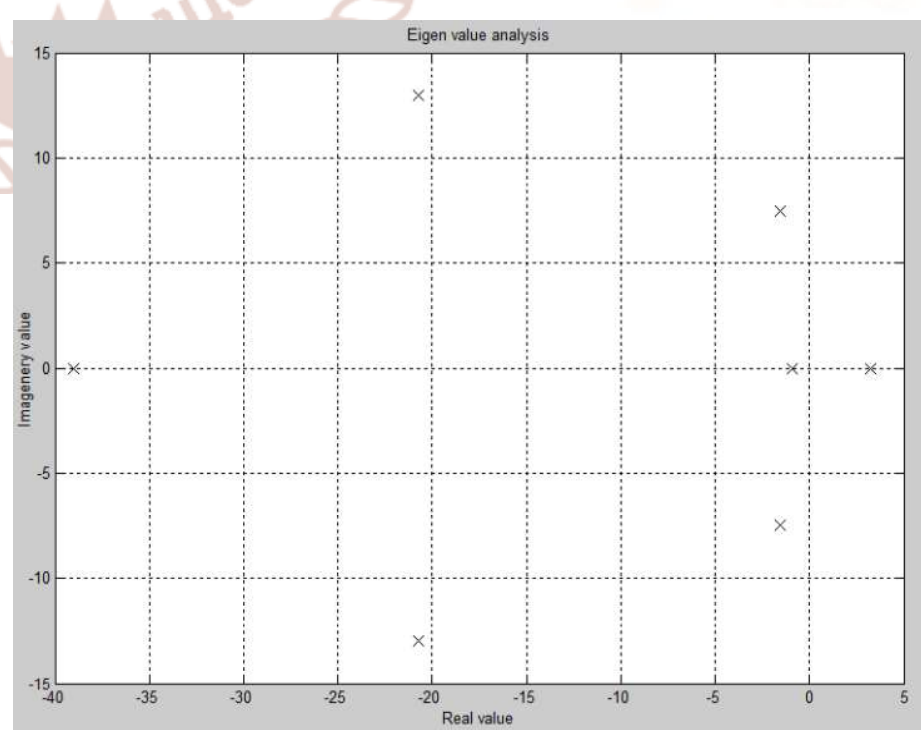

Fig. 12 Eigen values plot with STATCOM 
International Journal of Trend in Scientific Research and Development (IJTSRD) ISSN: 2456-6470

Table 1 Eigen value analysis

\begin{tabular}{|c|c|c|}
\hline Sr no. & Eigen value (with STATCOM) & Eigen value (with PSS) \\
\hline 1 & $-39.1176124890747+$ & $-19.1176124890747+$ \\
& $0.00000000000000 \mathrm{i}$ & $0.00000000000000 \mathrm{i}$ \\
\hline 2 & $-1.01459489109821+$ & $-1.01459489109821+$ \\
& $6.60501661154326 \mathrm{i}$ & $6.60501661154326 \mathrm{i}$ \\
\hline 3 & $-1.01459489109821-$ & $-1.01459489109821-$ \\
& $6.60501661154326 \mathrm{i}$ & $6.60501661154326 \mathrm{i}$ \\
\hline 4 & -0.739027952329247 & -0.739027952329247 \\
& $+0.00000000000000 \mathrm{i}$ & $+0.00000000000000 \mathrm{i}$ \\
\hline 5 & $-19.7196441434040+$ & $-9.71964414340402+$ \\
& $12.7407683082933 \mathrm{i}$ & $12.7407683082933 \mathrm{i}$ \\
\hline 6 & $-19.7196441434040-$ & $-9.71964414340402-$ \\
& $12.7407683082933 \mathrm{i}$ & $12.7407683082933 \mathrm{i}$ \\
\hline
\end{tabular}

After coordination work the Eigen values shifted left hand side of s-plane. So, small signal stability of the system increased.

\section{CONCLUSION}

From this thesis work outcome is that, the power system (small signal) stability will enhanced by the proper coordination of PSS and STATCOM. This is the new effective approach for improving the small signal stability. The Eigen values are shifted left hand side of the s-plane with co-ordination of PSS \& STATCOM. After using coordination of PSS \& STATCOM, settling time is decrease and system is stable in less time. This the new effective approach for improving the small signal stability of power stability.

\section{ACKNOWLEDGEMENT}

The authors are grateful to their family members, head of the department, colleagues, referees and the team of management for motivating, guiding and supporting to carry out the research activity for betterment of their career.

\section{REFERENCES}

1) L. Cong and Y. Wang" Co-ordinated control of generator excitation and STATCOM for rotor angle stability and voltage regulation enhancement of power systems.

2) Hitesh d. patel and charvi majmudar "fuzzy logic application to single machine power system
3) stabilizer" institute of technology, nirma university, Ahmedabad - 382 481, 08-10 December, 2011.

4) H.Boules,Senior Member, IEEE, S. Peres, T. Margotin, M.P. Houry, Member, IEEE "Analysis And Design Of A Robust Coordinated AVR/PSS" IEEE Transactions on Power Systems, Vol. 13, No. 2, May 1998.

5) Ahmad Rohani, M. Reza Safari Tirtashi, and Reza Noroozian "Combined Design of PSS and STATCOM Controllers for Power System Stability Enhancement" Journal of Power Electronics, Vol. 11, No. 5, September 2011.

6) S.Sowjanya, Prof.J.Srinivasarao "Design of FACTS device for the improvement of Power System Stability Using Mathematical Matching Controller" Iosr Journal Of Electrical and Electronics Engineering (Iosrjeee) Issn: 22781676 Volume 1, Issue 3 (July-Aug. 2012).

7) Ghazanfar Shahgholian, Pegah Shafaghi,Sepehr Moalem,Mehdi Mahdavian "Damping Power System Oscillations in Single-Machine InfiniteBus Power System Using a STATCOM" 2009 Second International Conference on Computer and Electrical Engineering.

8) Prabha Kundur,"Power System Stability and Control". New York: McGraw-Hill, 1994.

9) N.G. Hingorani and L.Gyugi,"Understanding FACTS -Concepts and Technology of flexible Ac Transmission Systems", Standard Publishers Distributors, IEEE Press, New York, 2001.

10) www.nptel.iitm.ac.in 